\title{
EFICIÊNCIA DO BIOCONTROLE POR Trichoderma sp. CONTRA Thielaviopsis paradoxa, AGENTE ETIOLÓGICO DA RESINOSE DO COQUEIRO
}

\section{EFFICIENCY OF BIOCONTROL BY Trichoderma sp. AGAINST Thielaviopsis paradoxa, ETHIOPIA AGENT OF COCONUT RESINOUS}

\author{
Cássia Cristina Chaves Pinheiro ${ }^{1}$; Aline Figueiredo Cardoso $^{2}$; Ana Karoliny Alves Santos ${ }^{3}$; \\ Paulo Manoel Pontes Lins ${ }^{4}$; Gisele Barata da Silva ${ }^{5}$
}

DOI: $\underline{\text { https://doi.org/10.31692/978-65-991061-7-0.183-190 }}$

\section{RESUMO}

A resinose do coqueiro, causada pelo fungo Thielaviopsis paradoxa, é uma das doenças mais agressivas da cultura, podendo causas grandes perdas econômicas. O controle biológico comumente vem se tornando uma alternativa viável ao uso de defensivos agrícolas para o controle de doenças. $\mathrm{O}$ uso de fungos do gênero Trichoderma vêm se demonstrando bastante promissor devido a gama de mecanismos de ação direta que possuem contra fitopatógenos. Desse modo, o objetivo deste trabalho foi avaliar o antagonismo in vitro de isolados de Trichoderma sp. com potencial no controle do fitopatógeno T. paradoxa. O delineamento experimental foi inteiramente ao acaso, foram utilizados para o experimento três isolados de Trichoderma sp. (T09, T17 e T19) isolados de rizosfera de plantios comercial de coqueiro e o controle ( $T$. paradoxa) e, quatro repetições. O teste de antagonismo utilizado foi de pareamento, onde em placas de Petri Petri $(\varnothing=08 \mathrm{~cm})$ contendo meio de cultura BDA( Batata-Dextrose- Àgar), foram adicionados discos de $5 \mathrm{~mm}$ de colônia dos fungos em pólos opostos das placas, a $5 \mathrm{~mm}$ de distância da borda, e incubados em temperatura ambiente, com fotoperíodo de $12 \mathrm{~h}$ claro/escuro por três dias. $\mathrm{O}$ experimento foi avaliado medindo-se o crescimento radial das colônias do patógeno na presença de cada antagonista, calculando-se o Índice de Velocidade de Crescimento Micelial (IVCM) e o Percentual de Inibição do Crescimento Radial (PICR) médio. A análise estatística de variância foi feita pelo teste $\mathrm{F}$ ( $\mathrm{p}$-valor $\leq 0.05$ ) e as médias de crescimento foram comparadas pelo teste de Scott-Knott (pvalor $\leq 0.05$ ). O programa utilizado para as análises foi o SISVAR, versão 5.6. Observou-se diferença estatística significativa no IVCM e PICR entre os tratamentos de $T$. paradoxa pareados com isolados Trichoderma e o tratamento controle. Todos os isolados foram eficientes no controle, apresentando-se desta forma, com agente de biocontrole potencial no crescimento micelial in vitro dedo fungo causador da doença.

Palavras-Chave: Antagonismo, Cocos nucifera, controle biológico, hiperparasitismo.

\begin{abstract}
The resinous coconut, the structure by the fungus Thielaviopsis paradoxa, is one of the most aggressive diseases of the crop, the cause of the great economic losses. The common biological control has become a viable alternative to the use of agricultural pesticides for the control of diseases. The use of fungi of the genus Trichoderma can be very promising due to a set of mechanisms of action that exist against phytopathogens. Thus, the objective of this work was to evaluate the in vitro antagonism of Trichoderma sp. with potential in the control

\footnotetext{
${ }^{1}$ Acadêmica de Agronomia, Universidade Federal Rural da Amazônia, cassiapinheiro002@gmail.com

2 Agrônoma e Doutoranda em Agronomia, Universidade Federal Rural da Amazônia, aline_f_cardoso@hotmail.com

${ }^{3}$ Acadêmica de Agronomia, Universidade Federal Rural da Amazônia, karol.ine20@ gmail.com

${ }^{4} \mathrm{Eng}^{\mathrm{o}} \mathrm{Agr}^{\mathrm{o}}$, Superintendente da empresa Socôco S.A Agroindústrias da Amazônia, pmplins@uol.com.br

${ }^{5} \mathrm{Dr}^{\mathrm{a}}$, Professora na Área de Microbiologia da Universidade Federal Rural da Amazônia, gisele.barata@ufra.edu.br
} 
of the phytopathogen T. paradoxa. The experimental design was completely randomized, were used for the experiment of three isolates of Trichoderma sp. (T09, T17 and T19) isolated from rhizosphere of commercial coconut and control plants $T$. paradoxa and four replicates. The antagonism test used was a pairing, where Petri Petri plates $(\varnothing=08 \mathrm{~cm})$ were placed with BDA (Potato-Dextrose-Àgar) culture medium, consisting of $5 \mathrm{~mm}$ of colony of fungi on opposite poles of plates, $5 \mathrm{~mm}$ away from the border, and incubated at room temperature, with the time of $12 \mathrm{~h}$ light / dark for three days. The experiment was mediated by the radial growth of the colonies of patients in the presence of each antagonist, calculating the Micellar Growth Rate Index (IVCM) and the Mean Radial Growth Inhibition Percentage (PICR). Statistical analysis of variance was performed using the F-test ( $p$-value $\leq 0.05)$ and as growth indicators were compared by the Scott-Knott test ( $\mathrm{p}$ value $=0.05$ ). The program used for the analyzes was SISVAR, version 5.6. In order to be able to significantly reduce the IVCM and the PICR between the treatments of $T$. paxis paired with Trichoderma and the control treatment. All the results were effective in the control, showing in this way, with potential biocontrol agent without mycelial growth in vitro finger fungus causing the disease.

Keywords: Antagonism, Cocos nucifera, biological control, hyperparasitism.

\section{INTRODUÇÃO}

Cocos nucifera é uma palmeira cultivada em cerca de 90 países e é um dos principais cultivos agrícolas no Brasil, sendo sua produção destinada para consumo in natura e segmentos industriais para produção alimentar, têxtil, arsenal, de ração animal e paisagismo (FONTENELE, 2005). Porém essa cultura pode ser acometida por diversas doenças de importância econômica, que podem ser de origem bacteriana, fúngica, viral ou causada por fitonematóides, levado a diminuição na produção podendo chegar até a perda total causando grandes prejuízos aos econômicos (WARWICK, 2016)

Dentre as doenças mais preocupantes na produção do coqueiro, destacam-se as causadas por fungos que atacam desde o início até o final do ciclo, afetando diferentes partes da planta (WARWICK et al., 2004). Entre os fungos causadores de doenças encontram-se Resinose, cujo o agente etiológico Thielaviopsis paradoxa (De Seynes) Höhn, caracterizandose pelo aparecimento de um liquido marrom-avermelhado que escorre através das rachaduras no tronco, que ao secar pode adquirir uma coloração avermelhada ou enegrecida e com o progresso da doença, as folhas acontece a diminuição de emissão de folhas, afinamento o tronco da região próxima à copa (WARWICK; PASSOS, 2009), podendo levar a morte da planta o que acaba tornando imprescindível a busca de técnicas eficiente para o seu controle (CARVALHO et al., 2011; CARVALHO et al., 2013)

Devido à crescente preocupação com relação ao uso de agrotóxicos e as questões ambientais com uso sustentável do meio ambiente, a busca por agentes de controle biológico para o manejo e doenças tornaram-se importantes (COMPANT et al., 2005; SOUSA; SOARES; GARRIDO, 2009).Os fungos do gênero Trichoderma são de grande importância 
econômica para a agricultura, devido a sua alta capacidade de promoção de crescimento em plantas e sua eficiência no controle de doenças em diversas plantas (MOHAMED; HAGGAG 2006, FORTES et al., 2007) agindo através de diversas maneiras, tais como antibiose, competição, parasitismo, hipovirulência, predação ou indução de defesa do hospedeiro (GAUCH, 1996). Todos esses fatores mostram que o Trichoderma é o agente de controle biológico de doenças de plantas mais estudado no Brasil e em outros países da América Latina (BETTIOL et al., 2008).

Diante disso, o objetivo do trabalho é avaliar a capacidade antagônica de isolados de Trichoderma com potencial para serem utilizados como agentes no biocontrole de Thielaviopsis paradoxa.

\section{FUNDAMENTAÇÃO TEÓRICA}

O fungo Thielaviopsis paradoxa ataca grande número de espécies vegetais de extrema importância econômica, causando doenças em culturas como cana-de-açúcar (Saccharum spp.), coco (Cocos nucifera L.), dendê (Elaeis guineinsis Jacq.), cacau (Theobroma cacao L.), banana (Musa spp.) e várias espécies de palmeiras, contribuindo para o aumento da fonte de inóculo (ELLIS, 1971; ELLIOT, 2009).

No coqueiro, as medidas utilizadas para o controle são: raspagem e pincelamento com piche ou alcatrão vegetal na região lesionada do estipe, junto com o fungicida tiofanato metílico; erradicação e queima das plantas severamente atacadas; monitoramento e controle do Rhynchophorus palmarum (principal vetor da doença) através de armadilhas (FERREIRA et al., 2010). Porém, essas medidas não vêm causando a eficiência desejada e a doença têm-se disseminado de forma rápida e progressiva por todas as regiões produtoras do país, principalmente no Norte e Nordeste (SILVA; SIQUEIRA. 2007).

$\mathrm{Na}$ busca de soluções para esses problemas, o emprego de técnicas alternativas ambientalmente corretas e economicamente viáveis, é primordial para a quebra do sistema de produção atual (BETTIOL; MORANDI, 2009) uma delas é o desenvolvimento de inoculantes à base de microrganismos promotores do crescimento e controle biológico de doenças em plantas (MACHADO et al., 2012).

Neste cenário, fungos do gênero Trichoderma têm destacada importância devido sua capacidade de adaptação em diversos ambientes e mecanismos de ação no controle de fitopatógenos, como produção de antibióticos voláteis e não-voláteis, competição por espaços e nutrientes, atividade enzimática hidrolítica e parasitismo (BRITO et al., 2014). Segundo Sousa et al., (2017), isolados do gênero Trichoderma proporcionou bons percentuais de 
inibição do crescimento do fungo Rizhoctonia solani, causador da mela em plantas de feijão caupi.

\section{METODOLOGIA}

Localização do experimento

O ensaio foi conduzido no Laboratório de Proteção de Plantas da Universidade Federal Rural da Amazônia-UFRA, campi de Belém, Pará ( $1^{\circ} 27^{\prime} 31^{\prime}$ S e 48 26’04.5” O), durante o período de setembro de 2018.

Obtenção dos isolados de Trichoderma sp.

Os isolados de Trichoderma sp. utilizados no experimento foram obtidos de amostras de solo coletadas na Fazenda Reunidas Sococo ( $1^{\circ} 13^{\prime} 26^{\prime \prime}$ S e $48^{\circ} 02$ ' 29” W) da Empresa Sococo Produtos Alimentícios S/A e se encontram depositados na coleção de microrganismos do Laboratório de Proteção de Plantas da Universidade Federal Rural da Amazônia-UFRA. Foram selecionados para os testes quatro isolados que apresentaram melhor desempenho em testes preliminares de promoção de crescimento in vivo.

Obtenção do isolado de T. paradoxa do coqueiro

O patógeno foi isolado de folhas com sintomas de Resinose no plantio da Empresa Sococo Produtos Alimentícios S/A. O material com sintomas da doença foi levado ao Laboratório de Proteção de Plantas para isolamento indireto do fungo, segundo Alfenas et al., (2007). As placas foram incubadas em câmaras de armazenamento do tipo BOD, à temperatura de $28 \pm 2^{\circ} \mathrm{C}$, com fotoperíodo de $12 \mathrm{~h}$ (claro/escuro), durante sete dias.

Antagonismo in vitro de isolados de Trichoderma sp. sobre T. paradoxa

O antagonismo de Trichoderma a $T$. paradoxa foi realizado pelo método de pareamento de colônias, sendo que as culturas do patógeno e dos antagonistas foram reativadas em meio de cultura BDA (Batata-Dextrose-Ágar) sete dias antes da instalação do experimento. Os discos de cultura do patógeno e dos antagonistas $(\varnothing=5 \mathrm{~mm})$ foram colocados em lados opostos e equidistantes de placas de Petri (5mm de distância da borda) contendo BDA, as quais foram incubadas em BOD (Demanda Biológica de Oxigênio), à temperatura de $28 \pm 2^{\circ} \mathrm{C}$, com fotoperíodo de $12 \mathrm{~h}$ (claro/ escuro).

Avaliação e analise estatística

A avaliação foi iniciada a partir de 24 horas da instalação do experimento, medindo-se diariamente o crescimento radial $(\mathrm{mm})$ das colônias, até o crescimento completo da testemunha na placa. Com os dados obtidos, foi calculado o Índice de Velocidade de Crescimento Micelial (IVCM), segundo equação adaptada de Oliveira (1991): $\operatorname{IVCM}=\frac{D-D a}{N}$ 
em que D é igual ao diâmetro atual da colônia, Da é o diâmetro do dia anterior e $\mathrm{N}$ é o número de dias após o início do experimento.

Foi determinada a percentagem de inibição do crescimento radial do patógeno nos tratamentos, em relação à testemunha, de acordo com a equação de Ezziyyani et al. (2004): $P I R C \frac{R 1-R 2}{R 1}$ sendo PICR $=\%$ de inibição de crescimento micelial, $\mathrm{R} 1=$ Raio da testemunha e $\mathrm{R} 2=$ Raio do tratamento.

O delineamento experimental foi inteiramente ao acaso, com cinco tratamentos, constituído de quatro isolados de antagonistas (T09, T17 e T19) e do tratamento controle, em quatro repetições. Os resultados obtidos apresentaram distribuição normal e foram submetidos à Análise de Variância, e as médias de IVCM e PIRC foram comparadas pelo teste de ScottKnott (p-valor $\leq$ 0.05), utilizando-se o programa SISVAR, versão 5.6 (FERREIRA, 2011).

\section{RESULTADOS E DISCUSSÃO}

Todos os isolados de Trichoderma sp. (T19, T09 E T17) tiveram efeito antagônico significativo sobre o crescimento micelial de $T$. paradoxa, quando comparados com ao tratamento controle (Figura 1).

Figura 1- Índice de Velocidade de Crescimento Micelial (IVCM) em cm/dia de T. paradoxa na presença de isolados de Trichoderma sp. Médias com letras iguais não diferem estatisticamente pelo teste de Scott-Knott ( $\mathrm{p} \leq$ $0,05)$.

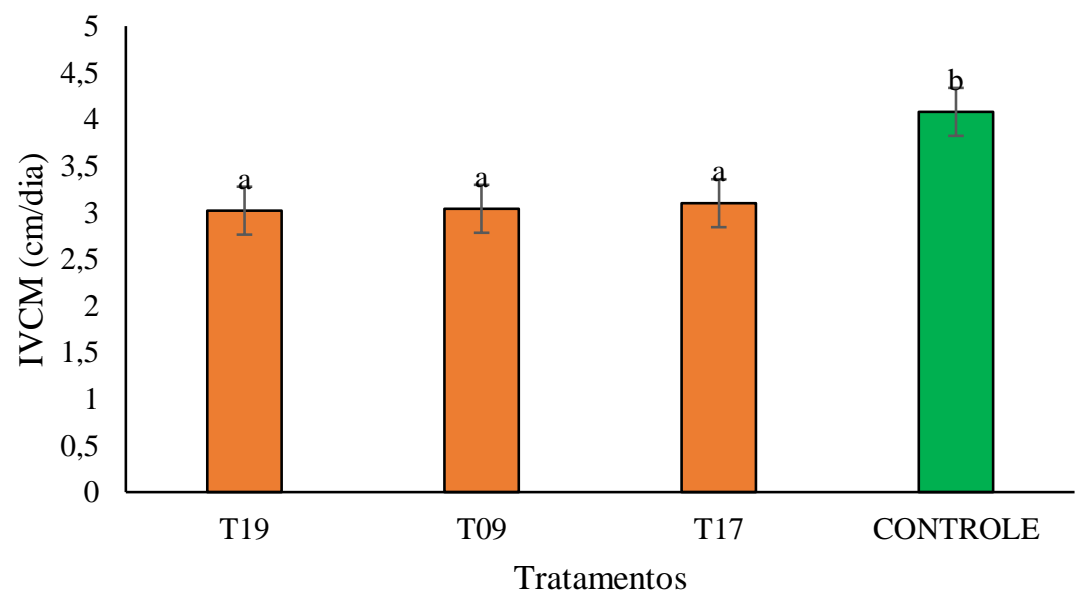

O crescimento micelial do patógeno foi de 3,02, 3,04, e 3,10 $\mathrm{cm}$ na presença dos isolados T19, T09 e T17, respectivamente, enquanto que no tratamento testemunha, o crescimento deste foi de 4,08 cm, sendo superior, portanto, àquele na presença dos antagonistas. Em todos os confrontos houve inibição do crescimento do patógeno como pode ser observado na Figura 2, em que todos os isolados diferiram do tratamento controle. 
Figura 2- Pareamento direto. Crescimento micelial de T. paradoxa na presença de isolados de Trichoderma sp. (A). e Imagem aproximada com seta indicando a zona de confronto entre o patógeno e o antagonista (B). Fonte:

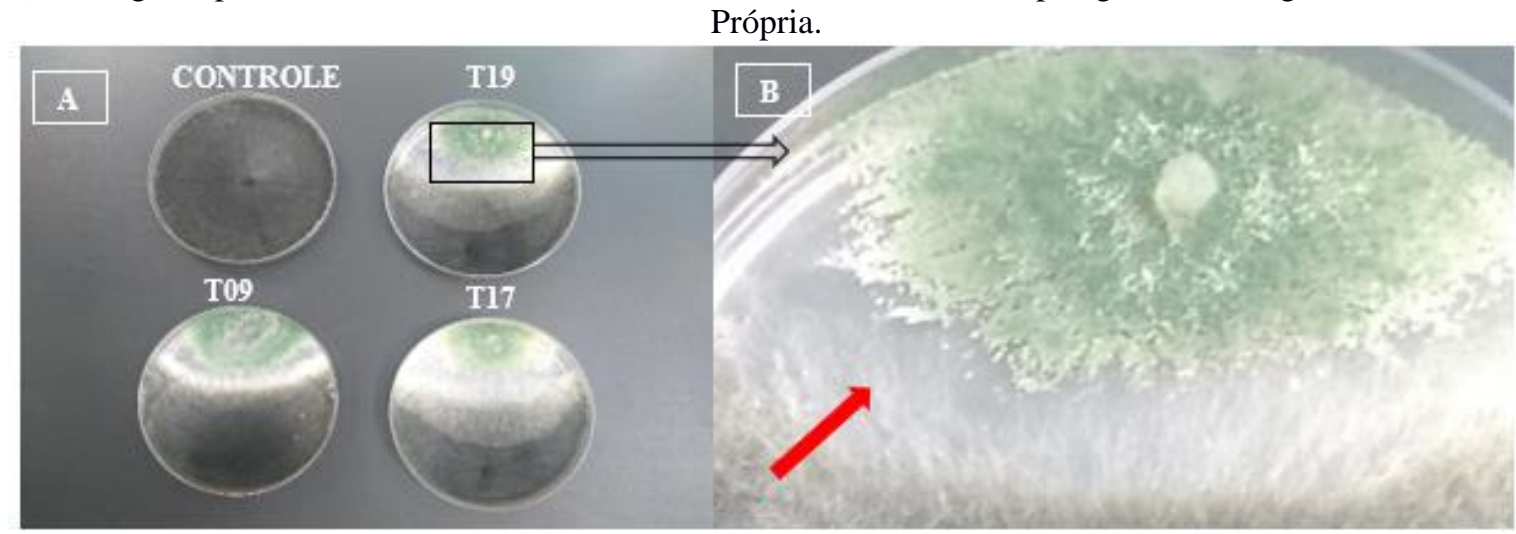

O isolado que resultou em maior PICR do patógeno foi T19, com 39,65\% seguido dos isolados T09 e T17 apresentaram inibição de 38,93\% e 36,50\%, respectivamente, porém, os seus valores médios de inibição não diferiram estatisticamente. Ou seja, todos os isolados evidenciaram potencial para futuros programas de controle biológico da Resinose em coqueiro (Tabela 1).

Tabela 1- Percentual médio de inibição do crescimento radial (PICR) de T. paradoxa por isolados de Trichoderma in vitro. Médias com letras iguais não diferem estatisticamente pelo teste de Scott- nott $\mathrm{p} \leq 0,05$ ). Fonte: Própria.

\begin{tabular}{cc}
\hline Isolados de Trichoderma sp. & PICR $(\%)$ \\
\hline T19 & $39,65 \mathrm{a}$ \\
T09 & $38,93 \mathrm{a}$ \\
T17 & $36,50 \mathrm{a}$ \\
\hline CV $(\boldsymbol{\%})$ & $\mathbf{9 , 0 9}$ \\
\hline
\end{tabular}

Foi possível visualizar, nesse trabalho que houve a inibição do crescimento do patógeno sobre a presença dos isolados de Trichoderma, mostrando a sua capacidade parasítica. Esses resultados evidenciam que, além do parasitismo direto, diversos mecanismos podem estar envolvidos na ação antagonista de fungos do gênero Trichoderma, tais como antibiose e competição (BENHAMOU; CHET 1996, FRAVEL 2005).

Resultados semelhantes ao que está sendo relatado no presente estudo foram descritos por Bhadra et al., (2014) onde foi comparando in vitro a eficiência do Trichoderma e fungicidas no controle de L. theobromae. Os autores encontraram percentual de inibição entre 60-80\% para as cepas utilizadas e consideram a utilização de fungos do gênero Trichoderma promissores.

\section{CONCLUSÕES}

Todos os isolados do gênero Trichoderma sp. são eficientes no controle in vitro do 
fungo Thievaliopsis paradoxa, evidenciando o seu potencial para futuros programas de controle biológico da doença Resinose em coqueiro.

\section{AGRADECIMENTOS}

A elaboração deste trabalho não seria possível sem a coloração da Universidade Federal Rural da Amazônia, o Laboratório de Proteção de Plantas, a Empresa Sococo Produtos Alimentícios S/A e a FAPESPA.

\section{REFERÊNCIAS}

ALFENAS, A.C.; FERREIRA, F.A.; MAFIA, R.G.; GONÇALVES, R.C. Isolamentos de fungos patogênicos. In: ALFENAS, A.C.; MAFIA, R.G. (Editores). Métodos em fitopatologia. Viçosa: Ed. UFV, p. 53-64. 2007.

BENHAMOU, N. \& CHET, I. Parasitism de Sclerotia of Sclerotium rolfsii by Trichoderma harzianum: ultrastructural and cytochemical aspects of the interaction. Phytopathology 86(4):405-416. 1996.

BETTIOL, W.; MORANDI, M.A.B. (org.). Biocontrole de Doenças de Plantas: uso e perspectivas. Jaguarina-SP: Embrapa meio Ambiente. p. 7-14, 2009.

BETTIOL, W.; MORANDI, M.A.B. Controle Biologico de Doenças de Plantas no Brasil. In: BHADRA, M.; KHAIR, A.; HOSSAIN, A.; SIKDER, M. Efficacy of Trichoderma spp. and fungicides against Lasiodiplodia theobromae. Journal of Scientific and Industrial Research, Bangladesh, v. 49, n. 2, p. 125-130, 2014.

CARVALHO, R. R. C. e. "Longevidade de Thielaviopsis paradoxa, agente causal da Resinose do coqueiro, em Rhynchophorus palmarum." Scientia Plena, Sergipe, v. 7, n. 4, p. 1-6, abr. 2011.

CARVALHO, R. R. D. E. et al. WARWICK "In vitro activity of essential oils of Lippia sidoides and Lippia gracilis and their major chemical components against Thielaviopsis paradoxa, causal agent of stem bleeding in coconut palms." Quimica Nova, São Paulo, v. 36, n. 2, p. 241-244, fev. 2013.

ELLIOT, M. Thielaviopsis trunk rot of palm. Flórida: University of Florida, 2009. 5 p. Disponível em: <edis.ifas.ufl.edu/pdffiles/PP/PP14300.pdf>. Acesso em 13, Set, 2018.

ELLIS, M. B. Dematiaceous hyphomycetes. Surrey: CAB-Commonwealth Mycological Institute, $608 \mathrm{p}, 1971$.

FERREIRA, D. F. Sisvar: a computer statistical analysis system. Ciência e Agrotecnologia, Lavras, v. 35, n. 6, p. 1039-1042, 2011.

FRAVEL, D.R. Commercialization and implementation of biocontrol. Ann. Rev. Phytopathol. 43(1):337-359. 2005.

MACHADO, D.F.M.; PARZIANELLO, F.R.; SILVA, A.C.F.; ANTONIOLLI, Z.I. Trichoderma no Brasil: o fungo e o bioagente. Revista de Ciências Agrárias, v.35, n.1, 2012. 
SILVA, S.D.V.M, MOURA, J.I.L; CERQUEIRA, A.R.R.N. Resinose do coqueiro na Bahia. Fitopatologia Brasileira S114. 2007.

Warwick, D. R. N.; Leal, E. C. A cultura do coqueiro: Doenças e métodos de controle. 2007. Disponível em: <http://sistemasdeproducao.cnptia.embrapa.br /FontesHTML/Coco/ACulturadoCoqueiro/doencas.htm> Acesso em 13, Set, 2018.

WARWICK, D. R.N.; FERREIRA, J.M.S.; PASSOS, E.E.M. Ocorrência de Resinose do estipe do coqueiro provocada por Chalara paradoxa em Sergipe. Fitopatologia Brasileira, Brasília, DF, 29(4):413, 2004. 